\title{
Is there a Kuznets Curve for Air Pollution and Economic Growth in Beijing-Tianjin-Hebei Region?
}

\author{
Zhang Xuefeng \\ School of Economics and Management \\ North China University of Technology \\ Beijing, China \\ E-mail: zxf511@163.com
}

\author{
Yan Mengyin \\ School of Economics and Management \\ North China University of Technology \\ Beijing, China \\ E-mail: 1209658646@qq.com
}

\begin{abstract}
The relationship between environmental pollution and economic growth in one area is inseparable. Beijing-TianjinHebei region as an important area of economic development also faces a lot of environmental pollution problems. In this paper, the Kuznets curve (EKC) was tested by using the statistical data of the per capita GDP and the discharge of major pollutants in Beijing Tianjin Hebei region from 2004 to 2015. The study found that per capita GDP increased by 1 yuan per capita, the average industrial pollution emissions decreased by 1.47 tons. Tianjin's industrial pollution emissions are associated with economic development with Kuznets inverted $U$ shape. As the economy grows, environmental pollution is reduced in Beijing. The relationship between the two in Hebei Province was $M$ shape, which means that with the growth of environmental pollution increased first, then gradually reduced, and finally exacerbated. This phenomenon occurs for about 6 years.
\end{abstract}

Keywords-Beijing-Tianjin-Hebei region, Kuznets curve, Economic growth, Environmental pollution

\section{INTRODUCTION}

Beijing-Tianjin-Hebei region has always been the focus of economic development area that is concerned by the government and the people. The economic development of Beijing, Tianjin and Hebei region has shown a good trend with the increase of state capital investment and the introduction of high and new technology. At the same time, the economic development is bound to have a regional impact on the environment. The State Environmental Protection Department issued the Beijing-Tianjin-Hebei coordinated development of ecological and environmental protection plan in December 30, 2016. It clarified the objectives, tasks, implementation path and system mechanism guarantee of eco - environmental protection.

Huang Jing, Chen Fenghua[1]established a human capital endogenous growth model on the relationship between environment and economic growth. This model leads to the conclusion that pollution control is introduced into the endogenous growth framework and concluded that China has been lacking enough attention to environmental pollution. $\mathrm{Hu}$ Youbiao and Zhu Zhengguo[2] have located the research area in Beijing. Based on the study of the air quality daily report of Beijing city from 2000 to 2004, it is found that the main pollutants in Beijing are inhalable particles.

Supported by the North China University of Technology outstanding young teacher training program, funded Beijing Social Science Foundation (Grant No.16LJC008) and Foundation for The Excellent Youth Scholars of Beijing (Grant No.2016000020124G021)
When the Grossman and Kruger[3]studied on the environmental effect problems, they analyzed the crosssectional data of 42 countries and studied the relationship between SO2, Dust and Suspended Particles and the three environmental quality indicators. It was found that the longterm relationship between environmental pollution and economic growth was inverted U-shaped, as reflected in the relationship between economic growth and income distribution. It got a conclusion that the per capita GDP in a country did not reach turning point of 4000-5000 US dollars (for the analysis of SO2), the economic growth tends to increase the environmental pressure through their model. On the contrary, once the per capita GDP exceeds the turning point of 40005000 US dollars, the economic growth tends to reduce environmental stress. Grossman and Kruger had used the two effects of per capita income change to explain the phenomenon: Economic development will bring more large-scale economic activities and resource demand, and thus there has a negative impact on the environment scale. But at the same time, the economic development has reduced the pollution emissions and improved the environmental quality through positive technological progress effect and structural effect. These two kinds of effects jointly determine the relationship between the quality of the environment and economic development of the inverted U-shaped curve relationship. A lot of economists carried out the theoretical and empirical analysis after the theory was put forward. Such as Shafik and Bandyopadhyay[4], Panayotou[5], Selden and Song [6], Coondoo[7], Llorca and Meunié[8] and Jalil and Mahmud [9]have carried out an empirical study on the relationship between environmental pollution indicators and economic growth respectively. Then, they all confirmed the existence of EKC theory. According to this theoretical background, this paper collected the data of per capita GDP and SO2 in the BeijingTianjin-Hebei region from 2004 to 2015 to analyze whether the economic growth and environmental pollution in the BeijingTianjin-Hebei region coincide with the Kuznets curve presented by Kuznets [10]. That is to say, if the per capita income from the lowest to the medium level, the income distribution situation tends to deteriorate. And then with the gradual development and improvement of the economy, the two finally will reach a more equitable distribution of income situation, showing inverted U shape. 


\section{MODEL AND ANALYSIS}

\section{A. Data and variable design}

This article collected the annual sulfur dioxide emissions $\left(\mathrm{SO}_{2}\right)$ in the three regions of Beijing, Tianjin and Hebei from 2004 to 2015, which is the main variable of industrial air pollution in China through the National Bureau of Statistics official website. We also collected data on per capita gross domestic product $\left(\mathrm{GDP}_{\mathrm{m}}\right)$ from 2004 to 2015 to study economic growth. The units of these two variables are tons and people / yuan, respectively.

$\mathrm{SO}_{2 \text { it }}$ represents the emissions of sulfur dioxide in the region $\mathrm{i}$ of the $\mathrm{t}$ year, $\mathrm{i}=\mathrm{BJ}, \mathrm{TJ}, \mathrm{HB}$.The $\mathrm{BJ}, \mathrm{TJ}, \mathrm{HB}$ respectively represents the Beijing, Tianjin and Hebei. GDP it represents the Per capita gross domestic product (GDP) in the region $\mathrm{i}$ of the $\mathrm{t}$ year. AR(1) represents the first order autoregressive term of the explanatory variable. $u_{i t}$ is a random interference term representing region i. $u_{i t} \sim N\left(0, \sigma^{2}\right), t=2004,2005, \ldots 2015$.

\section{B. Model}

In this paper, we use the idea of Kuznets and add a 1 order autoregressive, in order to solve the problem of autocorrelation. The general model we constructed is as follow:

$$
\mathrm{SO}_{2 \mathrm{it}}=\mathrm{a}_{0 \mathrm{i}}+\mathrm{a}_{1 \mathrm{i}} \mathrm{GDP}_{\mathrm{it}}+\mathrm{a}_{2 \mathrm{i}} \operatorname{AR}(1)+\mathrm{u}_{\mathrm{it}}
$$

$\mathrm{a}_{\mathrm{ki}}$ represents the Partial regression coefficient of variable $\mathrm{K}$ in the region $\mathrm{i}$. We get the figure 1 after statistical analysis.

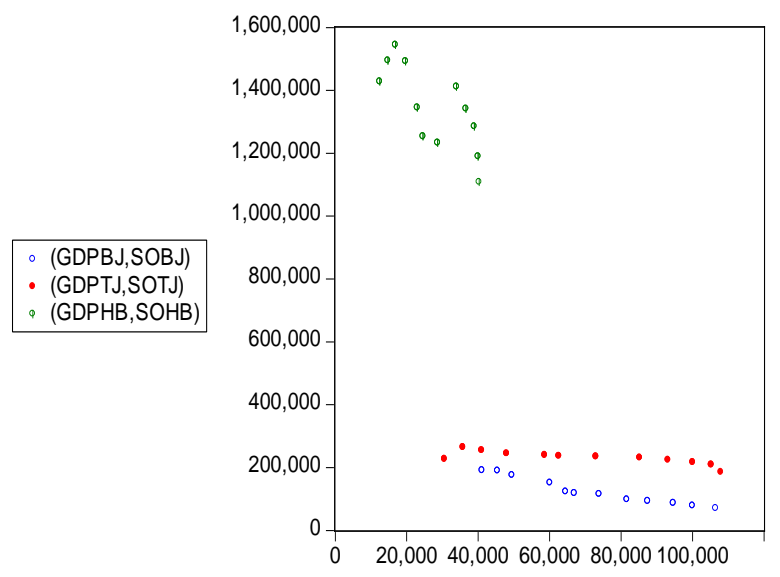

Fig. 1. The relationship between $\mathrm{GDP}_{\mathrm{m}}$ and $\mathrm{SO}_{2}$ in Beijing-Tianjin-Hebei region

The horizontal axis of Fig.1 represents the per capita GDP, and the vertical axis represents the emission of sulfur dioxide. The hollow circle represents the relationship between the emissions of sulfur dioxide and the per capita GDP in Beijing, and the two are in reverse direction. Solid circle represents the relationship on emissions of sulfur dioxide and the per capita GDP in Tianjin, and the relationship between the two is Kuznets inverted $U$ shape. This shows that the sulfur dioxide emissions have a trend of first increase and then decrease with economic growth. Semi hollow dots represent the relationship between the emissions of sulfur dioxide and the per capita GDP in Hebei Province. This shows that the sulfur dioxide emissions have a tendency to increase first and then decrease and then continue to increase and then decrease.

We constructed a fixed effect variable model with AR (1) after testing. The specific model established is:

$$
\mathrm{SO}_{2 \mathrm{it}}=\mathrm{a}_{0 \mathrm{i}}+\mathrm{a}_{1 \mathrm{i}} \mathrm{GDP}_{\mathrm{it}}+\mathrm{a}_{2 \mathrm{i}} \mathrm{AR}(1)+\mathrm{u}_{\mathrm{it}}
$$

In this paper, we use the FGLS method to estimate the disturbance term as the weight of each region. The estimated results are as follows:

TABLE I. RESULTS OF FIXED EFFECTS VARIABLE INTERCEPT ESTIMATION

\begin{tabular}{|l|l|l|l|l|}
\hline Variable & Coefficient & Std. Error & t-Statistic & Prob. \\
\hline C & 635244.9 & 20532.65 & 30.93828 & 0.0000 \\
\hline GDP? & -.473525 & 0.272004 & -.417289 & 0.0000 \\
\hline AR(1) & 0.672669 & 0.098865 & 6.803882 & 0.0000 \\
\hline Fixed Effects (Cross) & -409874.2 \\
\hline BJ--C & -281763.1 \\
\hline TJ--C & 691637.3 \\
\hline HB--C &
\end{tabular}

When the given significance level is $\alpha=0.05$, each variable has passed the test of significance. The sample regression functions are as follows:

$$
\begin{aligned}
\widehat{\mathrm{SO}_{2 \mathrm{BJ}}}= & 225370.7-1.47 \mathrm{GDP}_{\mathrm{BJ}}+0.67 \mathrm{AR}(1) \\
& (30.93) \quad(-5.42) \\
\widehat{\mathrm{SO}_{2 \mathrm{TJ}}=} & 353481.8-1.47 \mathrm{GDP}_{\mathrm{TJ}}+0.67 \mathrm{AR}(1) \\
& (30.93) \quad(-5.42) \\
\widehat{\mathrm{SO}_{2 \mathrm{HB}}=} & 1326882.2-1.47 \mathrm{GDP}_{\mathrm{HB}}+0.67 \mathrm{AR}(1)
\end{aligned}
$$$$
(-5.42)
$$

\section{CONCLUSIONS AND POLICY RECOMMENDATIONS}

Through theoretical and empirical research, this paper has the following important conclusions.

(1)Tianjin's industrial pollution emissions is associated with economic development with Kuznets inverted U shape. As the economy grows, environmental pollution is reduced in Beijing. The relationship between the two in Hebei Province was M shape, which means that with the growth of environmental pollution increased first, then gradually reduced, and finally exacerbated. This phenomenon occurs for about 6 years. The level of economic growth in Beijing has been in the leading position in the country because of the reform and open to the outside world. At the same time, compared to other cities in China, Beijing began an early economic transition, not just relied on labor and capital investment to promote economic growth. It has attracted more foreign investment and introduced high technology to develop the technology economy. Therefore, when Beijing develops economy as the city of technology can make a significant increase in per capita GDP, but also can reduce the emissions of industrial pollution. However, Tianjin's economic transformation is lagging behind in Beijing. Therefore, after the analysis of the samples we collected from 2004 to 2015, it is seen that the variables are in Kuznets' inverted $U$ shape in Tianjin. It indicated that Tianjin mainly 
relied on labor and capital to promote economic development from 2004 to 2006. From the beginning of 2007, with the introduction of technology and the development of high-tech industries, economic growth has been beginning to reduce the pollution of the environment, while Hebei Province is more special. As the country's large industrial enterprises are most located in Hebei Province, the economic type of Hebei Province is mainly industrial. The economic growth in Hebei Province is largely driven by low-cost labor under the combined action of policy and demographic dividends, which inevitably leads to economic growth that exacerbates environmental pollution. Although the introduction of technology will enable economic growth while reducing environmental pollution, the effect is temporary. Because hightech industry is not the main economic development type of Hebei Province, finally the relationship between economic growth and environmental pollution will show cyclical changes.

In the period from 2004 to 2015, the degree of environmental pollution is the most serious in Hebei, followed by Tianjin and the smallest in Beijing. Economic growth moves in the opposite direction to that of environmental pollution. Per capita GDP increases by 1 Yuan. While the average industrial pollution emissions decreases by 1.47 tons. After the supply-side structural reform, China's economic growth is mainly dependent on technology, labor and capital investment, so the pollution has been a certain degree of control.

The above contents are analyzed from the theoretical and empirical perspectives on the relationship between economic growth and environmental pollution. In fact, it also reminds us that the key to achieve sustainable development is to adopt increasingly cleaner production technology. All regions also need to provide the driving force for environmentally friendly economic growth and continue to carry out technological innovation to provide environmentally friendly economic growth. At the same time, environmental issues must be given sufficient attention under the pressure of environmental pollution. In the process of balanced economic growth, the intensity of environmental pollution control should be strengthened. The path of sustainable development in China is similar to the way of "Abatement after pollution". At present, China is far from achieving the balanced route of sustainable development. There are several reasons for this problem. First of all, from the economic type of Hebei Province can be seen that there is no fundamental change in the extensive economic growth mode of economic growth. Material capital and labor force are still the main imputes of China's economic growth. Secondly, environmental pollution in many places has not been paid enough attention, which is leading to the trend of environmental degradation increasing. Moreover, the environmental pollution control investment is not enough. Therefore, the environmental protection department is at a loss. In a conclusion, economic growth of China is partly to pay for the cost of environmental pollution. In this regard, our proposals are the following. First, the mode of economic growth should be actively changed .And the enterprises should speed up technological improvements. Although the empirical results show that the Beijing-Tianjin-Hebei region has achieved a healthy development of economic growth and environmental quality improvement, in view of Hebei Province, when the economy grows to a certain degree, environmental quality deteriorates with economic growth over the inflection point. China should continue to focus on the transformation of economic growth mode and try to change the traditional extensive mode of high energy consumption, high pollution reducing pollution emissions. At the same time, we must vigorously strengthen the production of technological improvements and promote cleaner production technology innovation and promotion to maintain economic and environmental sustainable development. Secondly, we need to continue to optimize the industrial structure. The impact of the industrial structure on the environment is very obvious, for example, the development of heavy industry will aggravate the deterioration of the environment. Although China's tertiary industry in the proportion of the national economy continues to increase, there is still a big gap compared with the developed countries that have a more than $70 \%$ level. The proportion of the secondary industry has not changed significantly, indicating that China needs to adjust the strategic adjustment of industrial structure as a way to accelerate the transformation of economic development direction. Beijing - Tianjin - Hebei region should actively develop the tertiary industry and find new economic growth point, while promoting the second industry structure optimization to encourage low-pollution and low energyconsuming industry development. Thirdly, the government departments to effectively increase investment in pollution control. In recent years the country began to increase pollution control investment, but did not play a real role. This means that in the pursuit of rapid economic growth in the process of generating a large number of environmental pollution through a small increase in pollution control investment cannot be resolved. Hence, China should continue to increase investment in pollution control in the future and strengthen the supervision and management of the use of investment to ensure that special investment can be implemented. Fourthly, to strengthen the environmental protection publicity, the pressure on the environment is increasingly prominent, because China is a populous country which has great contradictions between people and land. Beijing-Tianjin-Hebei region's population density is large, which requires the strengthening of environmental education and education to enhance people's awareness of environmental protection. The government should actively improve the relevant laws and regulations about serious pollution of the environment to regulate and control the behavior. It is not only beneficial to economic growth but also conducive to the promotion of environmental protection.

\section{REFERENCES}

[1] Huang Jing, Chen Shuanghua. Environmental pollution control and economic growth: Model and China 's Empirical Study. NANKAI ECONOMIC STUDIES, No.1, 2011(In Chinese)

[2] Hu Youbiao, Zhu Zhengguo. Analysis on the Change of Air Quality Time in Beijing. Northern environment, April 2010, Vol. 22, No. 2(In Chinese)

[3] Grossman G M, Krueger A B. Environmental Impacts of a North American Free Trade Agreement[R]. NBER Working Paper, No.3914, 1991. 
[4] Shafik N, Bandyopadhyay S. Economic Growth and Environmental Quality: Time Series and Cross-country Evidence[R] .Washington, DC. World Bank, 1992.

[5] Panayotou T. Empirical Tests and Policy Analysis of Environmental Degradation at Different Stages of Economic Development[R]. Geneva, 1993.

[6] Selden T M, Song D. Environmental Quality and Development: Is There a Kuznets Curve for Air Pollution Emissions[J].Journal of Environmental Economics and Management. 1994, 27(2): 147-162.
[7] Coondoo D, Dinda S. Causality between Income and Emission: A Country Group-specific Econometric Analysis[J]. Ecological Economics, 2002, 40(3): 351-367.

[8] Llorca M, Meunie A. SO2 Emissions and the Environmental Kuznets Curve: the Case of Chinese Provinces [J]. Journal of Chinese Economic and Business Studies, 2009, 7(1)

[9] Jalil A, Mahmud S. Environment Kuznets Curve for CO2Emissions: A Cointegration Analysis for China [J]. Energy Policy, 2009, 37(12): 5167-5172.

[10] Kuzets, S. Economic growth and income inequality. The American Economic Review,1995,45,1-28 